\title{
Assessment of Apparent Internal Carotid Tandem Occlusion on High-Resolution Vessel Wall Imaging: Comparison with Digital Subtraction Angiography
}

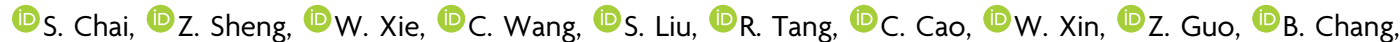 \\ (1)X. Yang, 기. Zhu, and (1DS. Xia
}

ow

\begin{abstract}
BACKGROUND AND PURPOSE: Not all tandem occlusions diagnosed on traditional vascular imaging modalities, such as MRA, represent actual complete ICA occlusion. This study aimed to explore the utility of high-resolution vessel wall imaging in identifying true ICA tandem occlusions and screening patients for their suitability for endovascular recanalization.
\end{abstract}

MATERIALS AND METHODS: Patients with no signal in the ICA on MRA were retrospectively reviewed. Two neuroradiologists independently reviewed their high-resolution vessel wall images to assess whether there were true tandem occlusions and categorized all cases into intracranial ICA occlusion, extracranial ICA occlusion, tandem occlusion, or near-occlusion. DSA classified patient images into the same 4 categories, which were used as the comparison with high-resolution vessel wall imaging. The suitability for recanalization of occluded vessels was evaluated on high-resolution vessel wall imaging compared with DSA.

RESULTS: Forty-five patients with no ICA signal on MRA who had available high-resolution vessel wall imaging and DSA images were included. Among the 34 patients (34/45, 75.6\%) with tandem occlusions on DSA, 18 cases also showed tandem occlusions on high-resolution vessel wall imaging. The remaining 16 patients, intracranial ICA, extracranial ICA occlusions and near-occlusions were found in 2, 6, and 8 patients, respectively, on the basis of high-resolution vessel wall imaging. A total of 20 cases (20/45, 44.4\%) were considered suitable for recanalization on the basis of both DSA and high-resolution vessel wall imaging. Among the 25 patients deemed unsuitable for recanalization by DSA, 11 were deemed suitable for recanalization by high-resolution vessel wall imaging.

CONCLUSIONS: High-resolution vessel wall imaging could allow identification of true ICA tandem occlusion in patients with an absence of signal on MRA. Findings on high-resolution vessel wall imaging can be used to screen more suitable candidates for recanalization therapy.

ABBREVIATIONS: EICA = extracranial ICA; IICA = intracranial ICA; HR-VWI = High-resolution vessel wall imaging

met-in ternal carotid artery occlusion is a relatively uncommonyet-important cause of TIAs and cerebral infarction. ${ }^{1}$ Tandem occlusion of the ICA, typically diagnosed on Doppler sonography, CTA, or MRA by the absence of flow, contrast media, or signal of the extracranial ICA (EICA) concomitant ipsilateral to the intracranial ICA (IICA), is often associated with a poor prognosis due to a low arterial recanalization rate. ${ }^{2-4}$

Received October 17, 2019; accepted after revision January 15, 2020.

From the Department of Radiology (S.C., W. Xie, S.L., R.T., S.X.), First Central Clinical College, Tianjin Medical University, Tianjin, China; Departments of Radiology and (S.C., W. Xie, S.L., R.T., S.X.), Tianjin First Central Hospital, Tianjin, China; Neurosurgery (Z.S., C.W., B.C.), Tianjin First Central Hospital, Tianjin, China; Department of Neurosurgery (W. Xin, X.Y.), Tianjin Medical University General Hospital, Tianjin, China; Department of Radiology (C.C.), Tianjin Huanhu Hospital, Tianjin, China; Department of Neurosurgery (Z.G.), Tianjin TEDA Hospital, Tianjin, China; and MR Collaboration (J.Z.), Siemens Healthcare Ltd., Beijing, China. This work was supported by a grant from the National Natural Science Foundation of China (NSFC 81871342).
However, not all tandem occlusions identified on these luminal imaging modalities represent actual complete ICA occlusion. Near-occlusion with or without full collapse (defined as prominent carotid bulb stenosis with a string-like or otherwise normalappearing distal lumen $)^{5,6}$ and isolated intracranial or extracranial occlusion caused by atherosclerosis or dissection may masquerade as complete occlusion of the ICA. ${ }^{7-10}$ In these cases of slow blood flow and altered flow dynamics, CTA or MRA acquisition can "outrun" the arrival of a blood signal or contrast media,

Please address correspondence to Shuang Xia, PhD, Department of Radiology, Tianjin First Central Hospital, No. 24, Fukang Rd, Nan Kai District, Tianjin, China; e-mail: xiashuang77@163.com

\footnotetext{
- Indicates open access to non-subscribers at www.ajnr.org

$\equiv$ Indicates article with supplemental on-line tables.

Indicates article with supplemental on-line photos.

http://dx.doi.org/10.3174/ajnr.A6452
}

AJNR Am J Neuroradiol 41:693-99 Apr 2020 www.ajnr.org 
resulting in inadequate arterial angiography and the appearance of an occlusion. This process can confound planning for recanalization treatment because many neurointerventionists would offer surgery to patients with apparent tandem occlusion on conventional luminal imaging if focal occlusion or near-occlusion was confirmed during intraoperative angiography. ${ }^{11-14}$ The process can also cause misclassification of patients with isolated ICA occlusion or near-occlusion during clinical trial screening if the evaluation is based solely on CTA or MRA. Consequently, accurate noninvasive imaging is necessary to visualize the true occlusion site and to help screen potential candidates for recanalization therapy.

High-resolution vessel wall imaging (HR-VWI) techniques allow direct characterization of the vessel wall and intraluminal status by suppressing the signal in flowing blood, ${ }^{15}$ providing information about the location, length, and etiology of the occlusion and the presence or absence of intraluminal thrombus. ${ }^{16,17}$ To the best of our knowledge, our study is the first to determine whether HR-VWI would enable superior identification of true tandem occlusions.

We hypothesized that HR-VWI could more accurately identify true tandem occlusion in patients with apparent ICA occlusion detected on MRA. The aims of this study were to explore the utility of HR-VWI for identifying true ICA tandem occlusions and to determine the suitability for endovascular recanalization in patients with an absence of signal on MRA compared with DSA.

\section{MATERIALS AND METHODS}

\section{Patient Selection and Data Collection}

This retrospective study was approved by the research ethics board at Tianjin First Central Hospital (project identification No. $2018 \mathrm{~N} 133 \mathrm{KY}$ ), and the informed consent requirement was waived. A total of 355 diagnostic HR-VWI scans were obtained from September 2016 to November 2018. Patients who had apparent tandem ICA occlusion on MRA and underwent both HR-VWI and DSA examinations were included in the study. The exclusion criteria were the following: 1) the presence of ICA signal, 2) the absence of DSA images for comparison, 3) insufficient vessel coverage or uninterpretable images due to motion artifacts, and 4) nonatherosclerotic or dissection occlusion, including Moyamoya disease, vasculitis, and trauma.

The patient data, including demographics, vascular risk factors (hypertension, hyperlipidemia, diabetes mellitus, coronary disease, prior stroke history, smoking, and alcohol intake), and their NIHSS scores, were retrospectively collected. The interval time from the HR-VWI examination to symptom onset and the time between HR-VWI and DSA were also recorded.

\section{MR Imaging Protocols}

All patients underwent routine brain MR imaging examinations and HR-VWI on a 3T system (Magnetom Prisma; Siemens, Erlangen, Germany) with a standard 64-channel head coil. Routine brain MRIs, including DWI and TOF-MRA, were initially performed for assessment of acute infarction and the vessels, respectively. The HR-VWI was performed by an inversion-recovery sampling perfection with application-optimized contrasts by using different flip angle evolution (IR-SPACE; Siemens) sequence to visualize the intraluminal status by suppressing blood flow and CSF signal, with the following parameters: $\mathrm{TR}=900 \mathrm{~ms}$; TE $=15 \mathrm{~ms}$; flip angle $=120^{\circ} ; \mathrm{FOV}=240 \times 210 \mathrm{~mm}^{2} ;$ matrix $=384 \times 336 ; 240$ slices with $0.55-\mathrm{mm}$ section thickness; reconstructed voxel size $=0.55 \times 0.55 \times 0.55 \mathrm{~mm}^{3} ;$ and acquisition time $=7$ minutes 43 seconds. Image reconstruction was performed with the $3 \mathrm{D}$ function of the PACS. On-line Table 1 shows more detailed sequence parameters.

\section{MRA Analysis}

All baseline MRA images were assessed by 2 diagnostic neuroradiologists (with 3 and 7 years of experience in neuroimaging, respectively) who were blinded to the DSA and HR-VWI findings for the apparent tandem occlusion in the ICA. "Apparent tandem occlusion" was defined as the absence of signal in the extracranial ICA concomitant ipsilateral to the intracranial ICA.

\section{HR-VWI Analysis}

Two additional diagnostic neuroradiologists (both with 3 years of experience in HR-VWI interpretation) who were both blinded to the DSA findings and clinical treatment information separately reviewed the HR-VWI and determined the presence or absence of occlusions from the carotid bulb to the circle of Willis. "Occlusion" was defined as discontinuation of lumen $>5 \mathrm{~mm}$ in length, ${ }^{18}$ which presented as no black-blood signal on HR-VWI.

The horizontal segment of the carotid canal was used as the landmark to divide the ICA into extracranial and intracranial segments. The occlusion types were categorized as EICA occlusion, IICA occlusion, tandem occlusion, and near-occlusion with or without full collapse. "Tandem occlusion" was defined as cervical carotid occlusion with a concomitant intracranial occlusion. ${ }^{19}$ Near-occlusion with and without full collapse was distinguished by prominent carotid bulb plaque with a string-like or more normal distal lumen, respectively. On-line Figure 1 shows different occlusion types on HR-VWI. The morphologic characteristics, including distal ICA reconstitution and the occlusion segment, were recorded. "Reconstitution" was defined as the ICA distal to the occlusion being visible. Segments of the ICA were evaluated on the basis of the classification criteria proposed by Bouthillier et al. $^{20}$

To evaluate intraobserver agreement, 1 reader reassessed the same images and measured vessel occlusion length 3 months after the first reading session. The measurement method of vessel occlusion length is shown on On-line Fig $2 A$. The cause of the occlusion, thrombus, or dissection with intramural hematoma was recorded, according to previously published parameters. $^{21}$

\section{Identification of Candidates Suitable for Endovascular Recanalization on the Basis of Occluded Vascular Features}

Criteria of apparent suitability for endovascular recanalization based on occlusion segment, occlusion type, and distal ICA reconstitution were proposed. ${ }^{2,22,23}$ Therefore, the vessels were further classified into 4 groups based on these morphologic features as follows: 
1. Suitable for recanalization: near-occlusion without full collapse.

2. Probably suitable for recanalization: focal occlusion at or above the clinoid segment, tandem occlusion with distal ICA reconstitution before the clinoid segment, and near-occlusion with full collapse.

3. Probably unsuitable for recanalization: tandem occlusion with distal ICA reconstitution at or above the clinoid segment.

4. Not suitable for recanalization: tandem occlusion without reconstitution.

\section{DSA Analysis}

Conventional selective cerebral angiography was performed using the transfemoral approach, including cervical and intracranial views in the anterior-posterior and lateral projections on the biplane angiography suite system (Allura Xper FD20 biplane system; Philips Healthcare, Best, the Netherlands). The injected volume of the contrast media was 6-8 mL.

Two interventional neuroradiologists (with 6 and 7 years of experience in interventional neuroradiology, respectively) reviewed all the DSA images in a blinded fashion to classify those images into the same 4 occlusion types, including IICA occlusion, EICA occlusion, tandem occlusion, and nearocclusion. The morphologic characteristics, including distal ICA reconstitution and occlusion segment, were defined using criteria similar to that for HR-VWI. If DSA showed no occlusion but only high-grade (90\%-99\%) stenosis in the carotid bulb with or without narrowing of the poststenotic ICA, the finding was deemed to show near-occlusion. ${ }^{24}$ The vessel occlusion length was measured by 1 of the readers (On-line Fig $2 B$ ). The suitability of the occluded vessels for endovascular recanalization was also classified into 4 groups using the same criteria as used for HR-VWI. Reperfusion was graded in patients who underwent recanalization treatment according to modified TICI perfusion categories, and procedural success was defined as TICI $2 \mathrm{~b}$ or $3 .^{7}$

\section{Statistical Analysis}

Statistical analysis was performed using SPSS, Version 22.0 (IBM, Armonk, New York) and GraphPad Prism software 5.0 (GraphPad Software, San Diego, California). Categoric variables were reported as proportions. Intra- and interneuroradiologist agreement regarding the qualitative parameters associated with the suitability for endovascular recanalization, occlusion site and reconstitution, were assessed using the Cohen $\kappa$. Disagreements in the interpretation of occlusion categories and suitability for endovascular recanalization were resolved by consensus review of the images. The Fisher exact test was used to calculate the statistical differences in the categoric proportions from contingency table analysis.

\section{RESULTS}

\section{Patient Characteristics}

In total, 355 patients with HR-VWI examinations were retrospectively analyzed; 78 patients were found to have an absence of signal in the ICA on MRA. Fifteen patients without DSA data for comparison were excluded; 4 patients were excluded due to insufficient vessel coverage or motion artifacts.

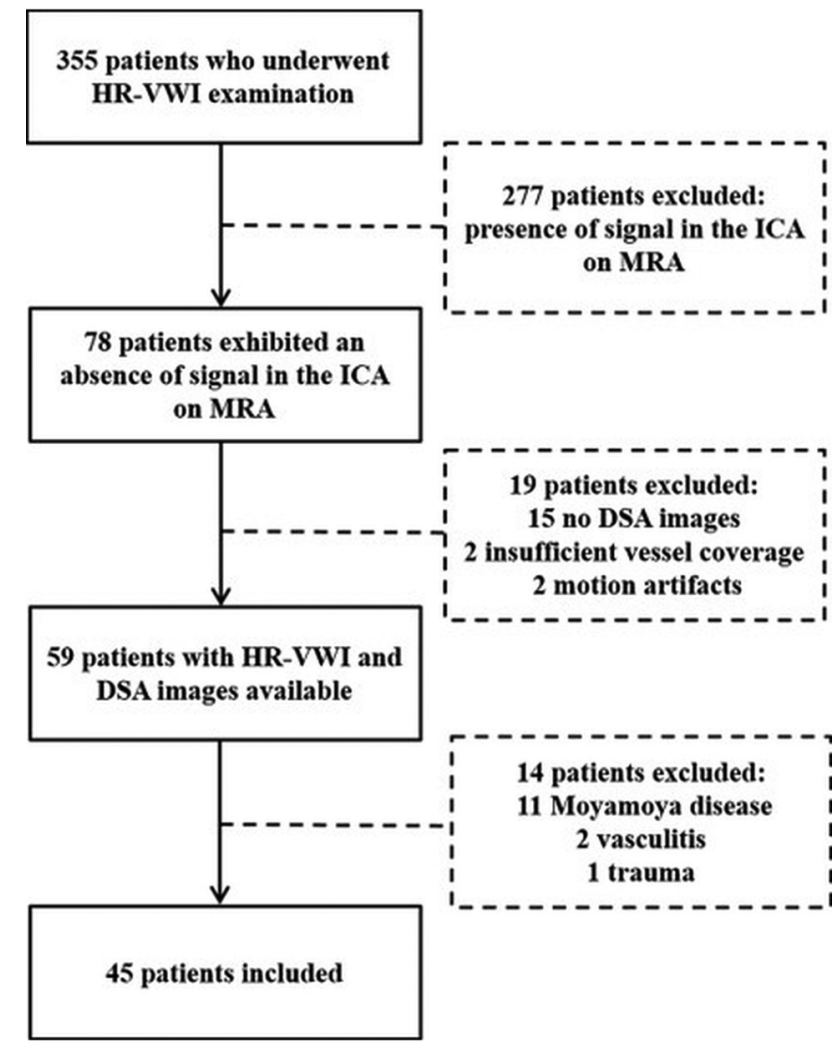

FIG 1. Flow chart of patient selection.

Patients with other causes of ICA occlusion, including 11 with Moyamoya disease, 2 with vasculitis, and 1 with trauma were also ruled out. Finally, 45 patients were included in the current study for analysis (Fig 1).

Of the 45 patients, $39(86.7 \%)$ were men and $6(13.3 \%)$ were women, with an average age of 62 years. The median and mean interval time between HR-VWI scanning and DSA was $6.0 \pm 3.5$ days (ranging from 1 to 15 days). More demographics and baseline characteristics are presented in On-line Table 2.

\section{Assessment Reproducibility}

Interobserver agreement coefficients regarding the occlusion category, reconstitution, and suitability for recanalization on HRVWI and DSA were almost perfect (On-line Table 3). Agreement coefficients were interpreted according to the methods described by Kundel and Polansky. ${ }^{25}$ Intraobserver agreement for the above qualitative analysis on HR-VWI was excellent, with $\kappa(95 \% \mathrm{CI})=$ 0.968 (0.907-1.000), 0.941 (0.861-1.000), and 0.945 (0.837$1.000)$, respectively.

\section{Findings on HR-VWI}

Among the 45 included cases with apparent occlusions on MRA, HR-VWI showed tandem occlusion in 18 cases (18/45, 40.0\%). All 18 cases also showed tandem occlusions on DSA (Table 1). Figure 2 shows an example of a case with matching classifications of tandem occlusion on both DSA and HR-VWI. In addition, dissection with intramural hematoma was detected on HR-VWI in $33.3 \%(6 / 18)$ of the cases of tandem occlusion. 


\begin{tabular}{|c|c|c|c|c|c|}
\hline \multirow[b]{2}{*}{ HR-VWI } & \multicolumn{4}{|c|}{ DSA } & \multirow[b]{2}{*}{ Total } \\
\hline & IICA Occlusion & EICA Occlusion & Tandem Occlusion & Near-Occlusion & \\
\hline IICA occlusion & $4(8.9 \%)$ & $0(0.0 \%)$ & $2(4.4 \%)$ & $0(0.0 \%)$ & $6(13.3 \%)$ \\
\hline EICA occlusion & $0(0.0 \%)$ & $1(2.2 \%)$ & 6 (13.3\%) & $0(0.0 \%)$ & 7 (15.6\%) \\
\hline Tandem occlusion $^{a}$ & $0(0.0 \%)$ & $0(0.0 \%)$ & 18 (40.0\%) & $0(0.0 \%)$ & $18(40.0 \%)$ \\
\hline Near-occlusion & $0(0.0 \%)$ & $0(0.0 \%)$ & 8 (17.8\%) & 6 (13.3\%) & 14 (31.1\%) \\
\hline Total & $4(8.9 \%)$ & $1(2.2 \%)$ & $34(75.6 \%)$ & $6(13.3 \%)$ & 45 (100\%) \\
\hline
\end{tabular}

${ }^{a}$ Tandem occlusion, concomitant extracranial ICA ipsilateral to the intracranial ICA occlusion. Fisher exact test: $P<.001$.
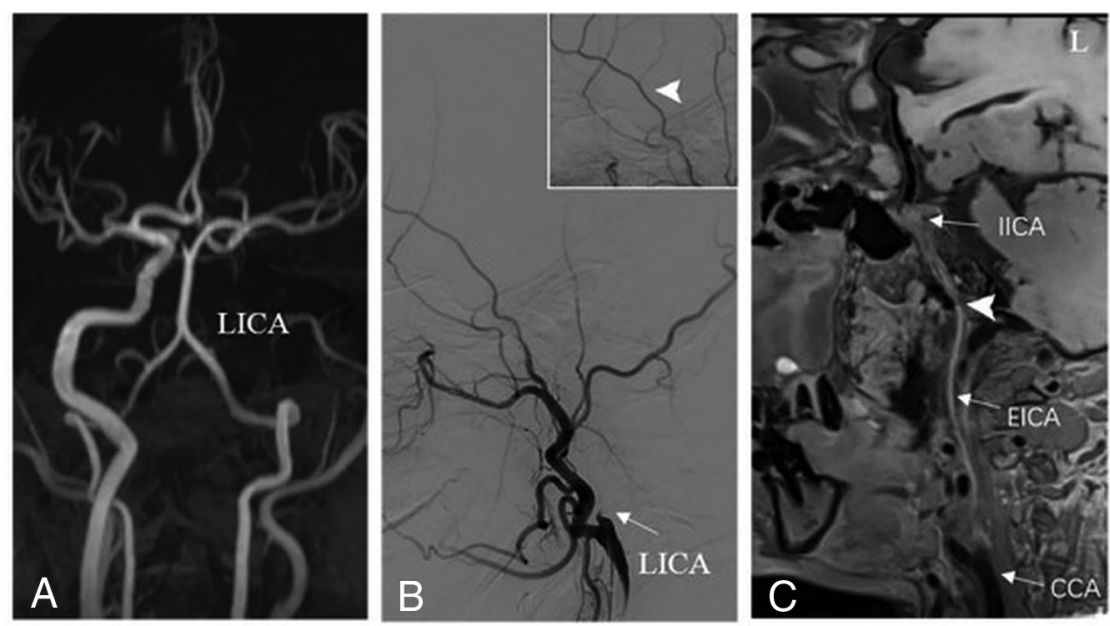

FIG 2. An example of tandem occlusion of the ICA. A, MRA shows an absence of signal in the left ICA. B, DSA presents contrast cutoff (arrow) at the level of the carotid bulb with distal ICA reconstitution (arrowhead). C, HR-VWI shows occlusion from the carotid bulb to the clinoid segment of the left ICA (arrowhead), with reconstitution at the supraclinoid segment, which was considered unsuitable for recanalization. LICA indicates left ICA.
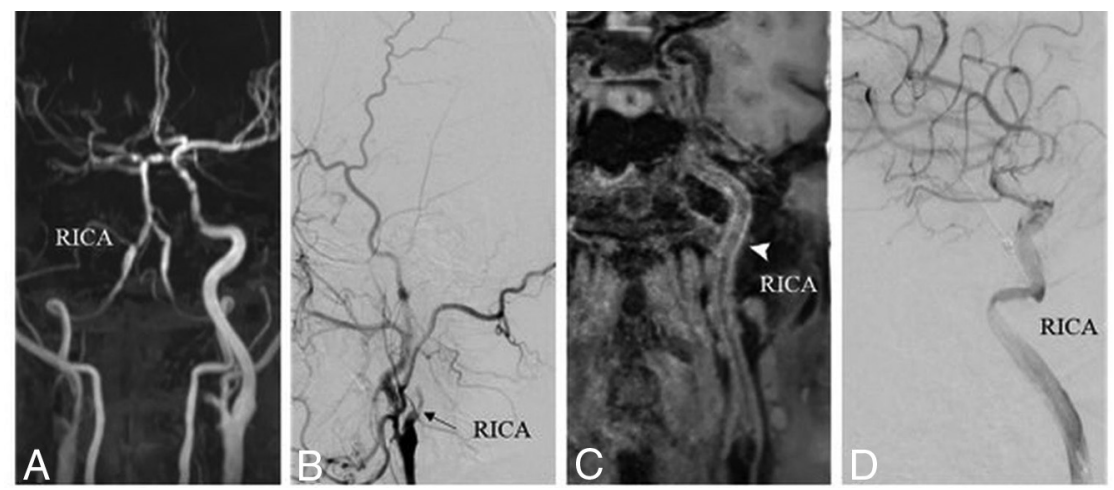

FIG 3. An example of apparent right internal carotid tandem occlusion on MRA $(A)$ and preoperative DSA ( $B$, arrow). C, HR-VWI shows a patent ICA with a narrow residual cavity (arrowhead), defined as near-occlusion with full collapse, which was considered suitable for recanalization. $D$, Postoperative DSA demonstrates successful recanalization with TICI 3. RICA indicates right ICA.

Figure 3 depicts a case with apparent internal carotid tandem occlusion on MRA and preoperative DSA, which was shown to display near-occlusion with full collapse on HR-VWI.

\section{Findings on DSA}

ICA tandem occlusions were detected on DSA in 34 of 45 (75.6\%) cases. Sixteen patients $(47.1 \%)$ had tandem occlusion on DSA, but HR-VWI showed IICA occlusion in 2, EICA occlusion in 6 , and near-occlusion in 8 patients. The remaining 11 (24.4\%) patients without tandem occlusion on DSA were correctly ruled out on HR-VWI. Among these patients, near-occlusion was observed in 6 (13.3\%) (of which 5 showed nearocclusion without full collapse and 1 showed near-occlusion with full collapse), isolated IICA occlusion was seen in $4(36.4 \%)$, and EICA occlusion in 1 (2.2\%) (Table 1 and On-line Fig $3 A$ ).

The length distribution of the tandem occlusion with the 2 imaging methods is presented in On line Fig $3 B$. The length of occlusion measured on HR-VWI was significantly shorter than that shown on DSA $(P<.001)$.

\section{Suitability for Recanalization Evaluated by HR-VWI versus DSA}

A total of 20 patients were deemed suitable for recanalization by both DSA and HR-VWI (Table 2). The extent of occlusion in these patients $(n=20)$ included 5 occlusions from the bulb to the cavernous ICA, 4 from the bulb to the petrous ICA, 1 at the cervical ICA, 4 localized at the supra-

In the 27 (60\%) remaining vessels, no tandem occlusions were found. Instead, IICA occlusions, EICA occlusions, and near-occlusions were observed in 6 (13.3\%), 7 (15.6\%), and 14 (31.1\%) cases, respectively. Of the 14 near-occlusion cases, 5 were near-occlusion without full collapse and 9 were near-occlusion with full collapse (Table 1 and On line Fig 3A). Therefore, near-occlusion with full collapse was most frequently categorized as tandem occlusion by DSA. clinoid ICA, 1 near-occlusion with full collapse at the ICA, and 5 near-occlusions without full collapse at the ICA. These numbers were 2, 2, 7, 6, 9, and 5, respectively, evaluated by HR-VWI (Fig 4).

In the remaining 25 patients who were deemed unsuitable for recanalization by DSA, 11 were found to be suitable for recanalization on the basis of HR-VWI, and 14 were considered 
Table 2: Performance of HR-VWI versus DSA in assessing tandem occlusion and suitability for recanalization of ICA ${ }^{\mathrm{a}}$

\begin{tabular}{lcccc}
\hline & \multicolumn{2}{c}{ DSA } & \multicolumn{2}{c}{ HR-VWI } \\
\cline { 2 - 5 } & Present & Absent & Suitable & Unsuitable \\
\hline HR-VWI present & $18(40.0 \%)$ & $0(0.0 \%)$ & $4(8.9 \%)$ & $14(31.1 \%)$ \\
HR-VWI absent & $16(35.6 \%)$ & $11(24.4 \%)$ & $27(60.0 \%)$ & $0(0.0 \%)$ \\
DSA (suitability for recanalization) & & & & \\
Suitable & $9(20.0 \%)$ & $11(24.4 \%)$ & $20(44.4 \%)$ & $0(0.0 \%)$ \\
Unsuitable & $25(55.6 \%)$ & $0(0.0 \%)$ & $11(24.4 \%)$ & $14(31.1 \%)$ \\
\hline
\end{tabular}

a "Present" means tandem occlusion-positive; "Absent" means tandem occlusion-negative. The table shows the proportional relationship between the presence of tandem occlusion and the suitablity for recanalization. The percentage was calculated on the basis of a total number of patients of 45 .

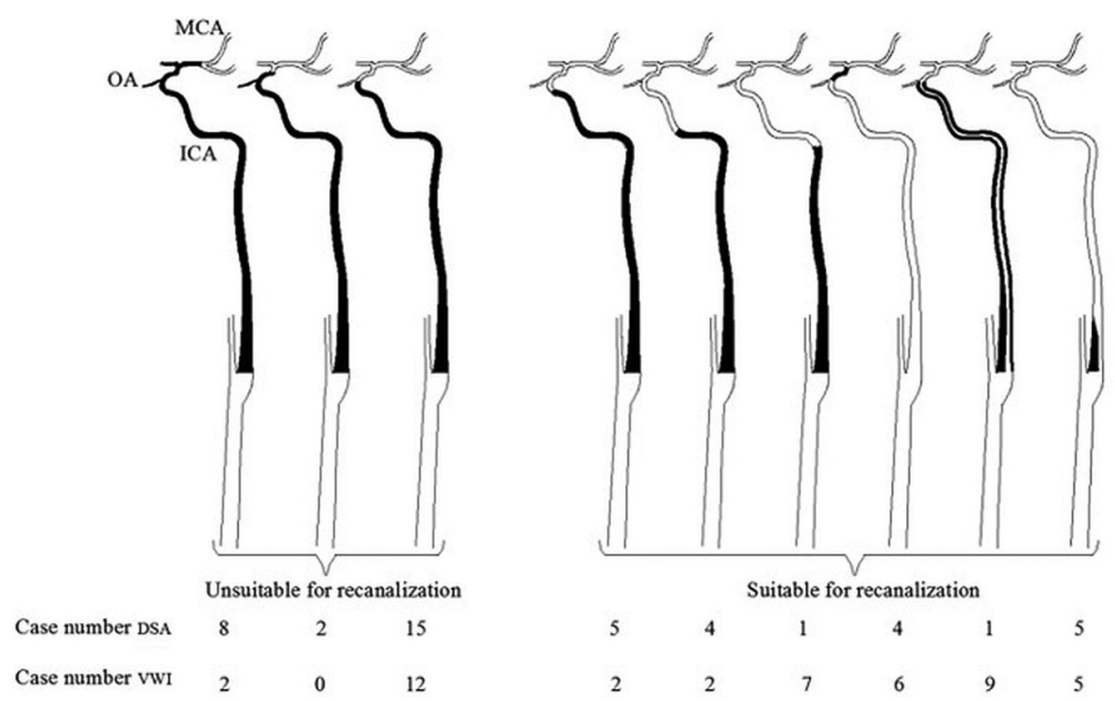

FIG 4. The extent of occlusion of 45 patients and their suitability for recanalization evaluated by DSA and VWI. The black part represents occlusion or near-occlusion. OA indicates ophthalmic artery.

unsuitable for recanalization by both HR-VWI and DSA (Table 2). The extent of occlusion in these 25 patients included 15 occlusions from the carotid bulb to the clinoid segment with reconstitution at the supraclinoid segment of the ICA, 2 occlusions from the bulb to the supraclinoid ICA, and 8 occlusions from the bulb to the MCA. These numbers were 12, 2, and 0 , respectively, evaluated by HR-VWI (Fig 4).

\section{Surgical Results for Endovascular Recanalization}

Twelve patients underwent recanalization surgery successfully with TICI $2 \mathrm{~b}$ or 3 among the 20 patients deemed suitable for recanalization by both DSA and HR-VWI. One patient presented with a history of recurrent stroke and underwent the operation successfully, with TICI 3 in the 11 patients deemed suitable for recanalization by HR-VWI but unsuitable by DSA. No operation was performed in the 14 patients deemed unsuitable for recanalization evaluated by both HR-VWI and DSA.

\section{DISCUSSION}

This study demonstrates that HR-VWI could allow identification of true ICA tandem occlusion in patients with apparent tandem occlusion on MRA. Furthermore, we proposed a method for preoperative evaluation of recanalization.
The study also shows that the arteries in approximately half of the patients with an apparent tandem ICA occlusion on DSA had patent or focal occlusion on HR-VWI. This finding may be due to the existence of pseudo-occlusion on luminal imaging techniques, including TOF-MRA, CTA, and DSA. Previous studies have indicated that even specialized radiologists may not be reliably able to distinguish true cervical occlusion from pseudo-occlusion in patients with ICA nonattenuation on single-phase CTA. ${ }^{8}$ Many studies have advocated the use of DSA to diagnose pseudo-occlusion. However, in the series studied by Grossberg et $\mathrm{al}^{7} 71 \%$ of patients also showed a pseudo-occlusion on DSA. The authors considered microcatheter exploration to be the only method able to accurately diagnose the location of the occlusion. This method, however, was invasive, with a substantial number of risks and potential complications. Thus, the noninvasive HR-VWI could serve as a more convenient technique for the identification of true ICA tandem occlusion.

Prominent proximal stenosis or occlusion of the extracranial carotid or distal occlusions in the intracranial ICA could give the appearance that the ICA was totally occluded on luminal imaging. The findings in our study were consistent with those of other recent studies. ${ }^{26-28}$ Patients with isolated vessel occlusion or nearocclusion could have overestimation and exaggeration on images captured with these luminal imaging techniques. Normal blood flow may be interrupted, possibly leading to an absence of signal or nonattenuation. ${ }^{8,29,30}$ To the best of our knowledge, there is no existing literature focusing on whether HR-VWI would enable superior identification of true tandem occlusion. As a result, the literature available to evaluate true ICA tandem occlusion using HR-VWI is limited. However, excellent interobserver agreement in our study suggests that detection of true occlusion sites by HRVWI in patients with an absence of signal on MRA is highly reproducible.

Recent research has shown that technical success rates in patients with reconstitution below the clinoid segment on preprocedural CTA were significantly higher than in those with reconstitution at or above the clinoid segment. ${ }^{22}$ Therefore, we regarded the clinoid segment as the standard for suitability of 
endovascular recanalization. Because DSA was also used for recanalization-procedure planning, a false-positive finding of tandem occlusion suggested that patients might be candidates for the recanalization treatment. This could significantly impact decision-making for some patients who might otherwise be excluded from selection as candidates for recanalization. ${ }^{31}$

Notably, 10 patients in our study had intramural hematomas, which have previously been described as being characteristic of dissection. ${ }^{32,33}$ Because the treatment for dissection is different from that of an isolated thrombus, this finding further proves the importance of HR-VWI.

Our study had several limitations. First, given the reliance on HR-VWI, there was a potential for ascertainment bias because these kinds of studies may have not been documented in previous literature and it was often difficult to have a criterion standard to confirm the occlusions. Second, this was a retrospective study with a relatively small sample size, but compared with other trials that focus on tandem or pseudo-occlusion, ${ }^{8,31,34-36}$ we had a similar or even relatively larger sample size. Third, although we proposed a method to identify candidates for recanalization, this method could not be well-validated due to a limited number of surgery cases. Therefore, larger sample sizes are needed in the future to validate the accuracy of the identification method. Finally, we could not completely exclude the possibility of recanalization during the period between HR-VWI and the DSA examination; the spontaneous recanalization rate of ICA occlusion is low, and the intervals are usually long, with an average interval of $>1$ year. ${ }^{37,38}$ We believe that the chance of spontaneous recanalization in our patients was small because the intervals between HR-VWI and DSA were short, with mean intervals of 6.8 days.

\section{CONCLUSIONS}

Compared with DSA, HR-VWI could allow identification of true ICA tandem occlusion in patients with an absence of signal on MRA. Findings on HR-VWI can be used to identify more suitable candidates for recanalization therapy.

\section{ACKNOWLEDGMENTS}

We would like to thank the study team and all the study participants.

\section{REFERENCES}

1. Flaherty ML, Flemming KD, McClelland R, et al. Population-based study of symptomatic internal carotid artery occlusion: incidence and long-term follow-up. Stroke 2004;35:e349-52 CrossRef Medline

2. Goyal M, Menon BK, van Zwam WH, et al; HERMES Collaborators. Endovascular thrombectomy after large-vessel ischaemic stroke: a meta-analysis of individual patient data from five randomised trials. Lancet 2016;387:1723-31 CrossRef Medline

3. Rubiera M, Ribo M, Delgado-Mederos R, et al. Tandem internal carotid artery/middle cerebral artery occlusion: an independent predictor of poor outcome after systemic thrombolysis. Stroke 2006;37:2301-05 CrossRef Medline

4. Verlato F, Camporese G, Bernardi E, et al. Clinical outcome of patients with internal carotid artery occlusion: a prospective follow-up study. J Vasc Surg 2000;32:293-98 CrossRef Medline
5. Bartlett ES, Walters TD, Symons SP, et al. Diagnosing carotid stenosis near-occlusion by using CT angiography. AJNR Am J Neuroradiol 2006;27:632-37 Medline

6. Fox AJ, Eliasziw M, Rothwell PM, et al. Identification, prognosis, and management of patients with carotid artery near occlusion. AJNR Am J Neuroradiol 2005;26:2086-94 Medline

7. Grossberg JA, Haussen DC, Cardoso FB, et al. Cervical carotid pseudo-occlusions and false dissections: intracranial occlusions masquerading as extracranial occlusions. Stroke 2017;48:774-77 CrossRef Medline

8. Diouf A, Fahed R, Gaha M, et al. Cervical internal carotid occlusion versus pseudo-occlusion at CT angiography in the context of acute stroke: an accuracy, interobserver, and intraobserver agreement study. Radiology 2018;286:1008-15 CrossRef Medline

9. Lee D, Heo SH, Kim EJ, et al. Pseudo-occlusion of the extracranial carotid artery caused by intracranial carotid artery stenosis. Neurol Sci 2012;33:1201-03 CrossRef Medline

10. Kao HL, Lin MS, Wang CS, et al. Feasibility of endovascular recanalization for symptomatic cervical internal carotid artery occlusion. J Am Coll Cardiol 2007;49:765-71 CrossRef Medline

11. Gil-Peralta A, González A, González-Marcos JR, et al. Internal carotid artery stenting in patients with symptomatic atheromatous pseudo-occlusion. Cerebrovasc Dis 2004;17(Suppl 1):105-12 CrossRef Medline

12. O'Leary DH, Mattle H, Potter JE. Atheromatous pseudo-occlusion of the internal carotid artery. Stroke 1989;20:1168-73 CrossRef Medline

13. Greiner $\mathrm{C}$, Wassmann $\mathrm{H}$, Palkovic $\mathrm{S}$, et al. Revascularization procedures in internal carotid artery pseudo-occlusion. Acta Neurochir (Wien) 2004; 146:237-43; discussion 243 CrossRef Medline

14. Rothwell PM, Eliasziw M, Gutnikov SA, et al; Carotid Endarterectomy Trialists' Collaboration. Analysis of pooled data from the randomised controlled trials of endarterectomy for symptomatic carotid stenosis. Lancet 2003;361:107-16 CrossRef Medline

15. Bhogal $\mathrm{P}$, Navaei E, Makalanda HL, et al. Intracranial vessel wall MRI. Clin Radiol 2016;71:293-303 CrossRef Medline

16. Naggara $\mathrm{O}$, Louillet $F$, Touzé $E$, et al. Added value of high-resolution MR imaging in the diagnosis of vertebral artery dissection. AJNR Am J Neuroradiol 2010;31:1707-12 CrossRef Medline

17. Ryoo S, Lee MJ, Cha J, et al. Differential vascular pathophysiologic types of intracranial atherosclerotic stroke: a high-resolution wall magnetic resonance imaging study. Stroke 2015;46:2815-21 CrossRef Medline

18. Chen YH, Leong WS, Lin MS, et al. Predictors for successful endovascular intervention in chronic carotid artery total occlusion. JACC Cardiovasc Interv 2016;9:1825-32 CrossRef Medline

19. Malik AM, Vora NA, Lin R, et al. Endovascular treatment of tandem extracranial/intracranial anterior circulation occlusions: preliminary single-center experience. Stroke 2011;42:1653-57 CrossRef Medline

20. Bouthillier A, van Loveren HR, Keller JT. Segments of the internal carotid artery: a new classification. Neurosurgery 1996;38:425-32; discussion 432-33 CrossRef Medline

21. Bachmann R, Nassenstein I, Kooijman H, et al. High-resolution magnetic resonance imaging (MRI) at 3.0 Tesla in the short-term follow-up of patients with proven cervical artery dissection. Invest Radiol 2007;42:460-66 CrossRef Medline

22. Chen YH, Kao HL. Predicting procedure successful rate and 1-year patency after endovascular recanalization for chronic carotid artery occlusion by CT angiography. Int J Cardiol 2017;229:59 CrossRef Medline

23. Marnat G, Mourand I, Eker O, et al. Endovascular management of tandem occlusion stroke related to internal carotid artery dissection using a distal to proximal approach: insight from the RECOST study. AJNR Am J Neuroradiol 2016;37:1281-88 CrossRef Medline

24. Chen CJ, Lee TH, Hsu HL, et al. Multi-slice CT angiography in diagnosing total versus near occlusions of the internal carotid 
artery: comparison with catheter angiography. Stroke 2004;35:8385 CrossRef Medline

25. Kundel HL, Polansky M. Measurement of observer agreement. Radiology 2003;228:303-08 CrossRef Medline

26. Duijsens HM, Spaander F, van Dijk LC, et al. Endovascular treatment in patients with acute ischemic stroke and apparent occlusion of the extracranial internal carotid artery on CTA. J Neurointerv Surg 2015;7:709-14 CrossRef Medline

27. Kim JJ, Dillon WP, Glastonbury CM, et al. Sixty-four-section multidetector CT angiography of carotid arteries: a systematic analysis of image quality and artifacts. AJNR Am J Neuroradiol 2010;31:9199 CrossRef Medline

28. Marquering HA, Nederkoorn PJ, Beenen LF, et al. Carotid pseudoocclusion on CTA in patients with acute ischemic stroke: a concerning observation. Clin Neurol Neurosurg 2013;115:1591-94 CrossRef Medline

29. Huston J, Lewis $\mathrm{BD}$, Wiebers DO, et al. Carotid artery: prospective blinded comparison of two-dimensional time-of-flight MR angiography with conventional angiography and duplex US. Radiology 1993;186:339-44 CrossRef Medline

30. Atlas SW. MR angiography in neurologic disease. Radiology 1994;193:1-16 CrossRef Medline

31. Ng FC, Choi PM, Datta M, et al. Perfusion-derived dynamic 4D CT angiography identifies carotid pseudo-occlusion in hyperacute stroke. J Neuroimaging 2016;26:588-91 CrossRef Medline

32. Bachmann R, Nassenstein I, Kooijman H, et al. Spontaneous acute dissection of the internal carotid artery: high-resolution magnetic resonance imaging at 3.0 Tesla with a dedicated surface coil. Invest Radiol 2006;41:105-11 CrossRef Medline

33. Coppenrath E, Lenz O, Sommer N, et al. Clinical significance of intraluminal contrast enhancement in patients with spontaneous cervical artery dissection: a black-blood MRI study. Rofo 2017;189:624-31 CrossRef Medline

34. Fujimoto S, Toyoda K, Kishikawa K, et al. Accuracy of conventional plus transoral carotid ultrasonography in distinguishing pseudoocclusion from total occlusion of the internal carotid artery. Cerebrovasc Dis 2006;22:170-76 CrossRef Medline

35. Kappelhof M, Marquering HA, Berkhemer OA, et al; MR CLEAN Investigators. Accuracy of CT angiography for differentiating pseudo-occlusion from true occlusion or high-grade stenosis of the extracranial ICA in acute ischemic stroke: a retrospective MR CLEAN substudy. AJNR Am J Neuroradiol 2018;39:89298 CrossRef Medline

36. Park SE, Choi DS, Baek HJ, et al. Endovascular therapy of acute ischemic stroke related to tandem occlusion: comparison of occlusion and severe stenosis of the proximal cervical internal carotid artery. Br J Radiol 2018 Dec 3:20180051. [Epub ahead of print] CrossRef Medline

37. Shchanitsyn IN, Maksyushina TD, Titova YI, et al. Spontaneous recanalization of chronic occlusion of the internal carotid artery [in English, Russian]. Angiol Sosud Khir 2015;21:124-35 Medline

38. Nozaki T, Hiramatsu H, Yamashita S, et al. Spontaneous multiplechannel recanalization of internal carotid artery occlusion with unusual radiological features. Clin Neuroradiol 2014;24:73-75 CrossRef Medline 